\title{
BMJ Open Incidence of delirium in the Canadian emergency department and its consequences on hospital length of stay: a prospective observational multicentre cohort study
}

Marcel Émond, ${ }^{1,2,3,4,5}$ Valérie Boucher, ${ }^{1,3,4,6}$ Pierre-Hugues Carmichael, ${ }^{4}$ Philippe Voyer, ${ }^{1,4,7}$ Mathieu Pelletier, ${ }^{3,8}$ Émilie Gouin, ${ }^{9}$ Raoul Daoust, ${ }^{10,11}$ Simon Berthelot, ${ }^{1,3,2}$ Marie-Eve Lamontagne, ${ }^{3,6}$ Michèle Morin, ${ }^{1,3}$ Stéphane Lemire, ${ }^{1,3,4}$ Thien Tuong Minh Vu, ${ }^{12,13,14}$ Alexandra Nadeau, ${ }^{1,3,4,6}$ Marcel Rheault, ${ }^{15}$ Lucille Juneau, ${ }^{16}$ Natalie Le Sage, ${ }^{1,3,2}$ Jacques Lee ${ }^{17,18}$

To cite: Émond M, Boucher V, Carmichael P-H, et al. Incidence of delirium in the Canadian emergency department and its consequences on hospital length of stay: a prospective observational multicentre cohort study. BMJ Open 2018:8:e018190. doi:10.1136/ bmjopen-2017-018190

- Prepublication history for this paper is available online. To view these files, please visit the journal online (http://dx.doi. org/10.1136/bmjopen-2017018190).

Received 16 June 2017 Revised 30 January 2018 Accepted 2 February 2018

Check for updates

For numbered affiliations see end of article.

Correspondence to

Dr Marcel Émond;

marcel.emond@fmed.ulaval.ca

\section{ABSTRACT}

Objective We aim to determine the incidence of delirium and describe its impacts on hospital length of stay (LOS) among non-delirious community-dwelling older adults with an 8-hour exposure to the emergency department (ED) environment.

Design This is a prospective observational multicentre cohort study (March-July 2015). Patients were assessed two times per day during their entire ED stay and up to 24 hours on hospital ward.

Setting The study took place in four Canadian EDs. Participants 338 included patients: (1) aged $\geq 65$ years; (2) who had an ED stay $\geq 8$ hours; (3) were admitted to hospital ward and (4) were independent/semiindependent.

Main outcome(s) and measure(s) The primary outcomes of this study were incident delirium in the ED or within 24 hours of ward admission and ED and hospital LOS. Functional and cognitive status were assessed using validated Older Americans Resources and Services and the modified Telephone Interview for Cognitive Status tools. The Confusion Assessment Method was used to detect incident delirium. Univariate and multivariate analyses were conducted to evaluate outcomes.

Results Mean age was $76.8( \pm 8.1), 17.7 \%$ were aged $>85$ years old and $48.8 \%$ were men. The mean incidence of delirium was $12.1 \%(n=41)$. Median IQR ED LOS was 32.4 (24.5-47.9) hours and hospital LOS was 146.6 (75.2267.8) hours. Adjusted mean hospital LOS was increased by 105.4 hours ( 4.4 days) $(95 \% \mathrm{Cl} 25.1$ to $162.0, \mathrm{P}<0.001)$ for patients who developed an episode of delirium compared with non-delirious patient.

Conclusions An incident delirium was observed in one of eight independent/semi-independent older adults after an 8-hour ED exposure. An episode of delirium increases hospital LOS by 4 days and therefore has important implications for patients and could contribute to ED overcrowding through a deleterious feedback loop.
Strengths and limitations of this study

- Largest prospective study on incident delirium in the emergency department.

- A systematic screening of delirium at study entry was realised with a validated tool.

- Multiple patient assessments for incident delirium were conducted.

- Study population was limited to independent/semiindependent elders, which may limit external validity of the findings.

- Hospital length of stay was adjusted for potential confounders relating to geriatric care.

\section{INTRODUCTION}

In 2016, the youngest of the 'baby boomers' turned 50 years old and people aged 65 and older represented $18.1 \%$ of the population in Quebec. ${ }^{1}$ It is foreseen that by 2031, the proportion of older adults aged over 65 will nearly double, with a major increase among those aged 85 and older. ${ }^{2}$ Over the coming decades, those demographic trends will fundamentally change the make-up of the population served by Quebec emergency departments (EDs). Older adults are already the main users of emergency healthcare services $^{3-5}$ and in 2012-2013, 40\% of ED stretchers were occupied by patients aged over $65 .{ }^{6}$ Furthermore, patients over 75 years of age have the highest ED visit rate of any age group and in 2012-2013 those patients occupied $25 \%$ of ED stretchers. ${ }^{7} 8$ Those numbers will only increase over time as the older adult population grows and this 'silver tsunami ${ }^{9}$ will have major consequences on 


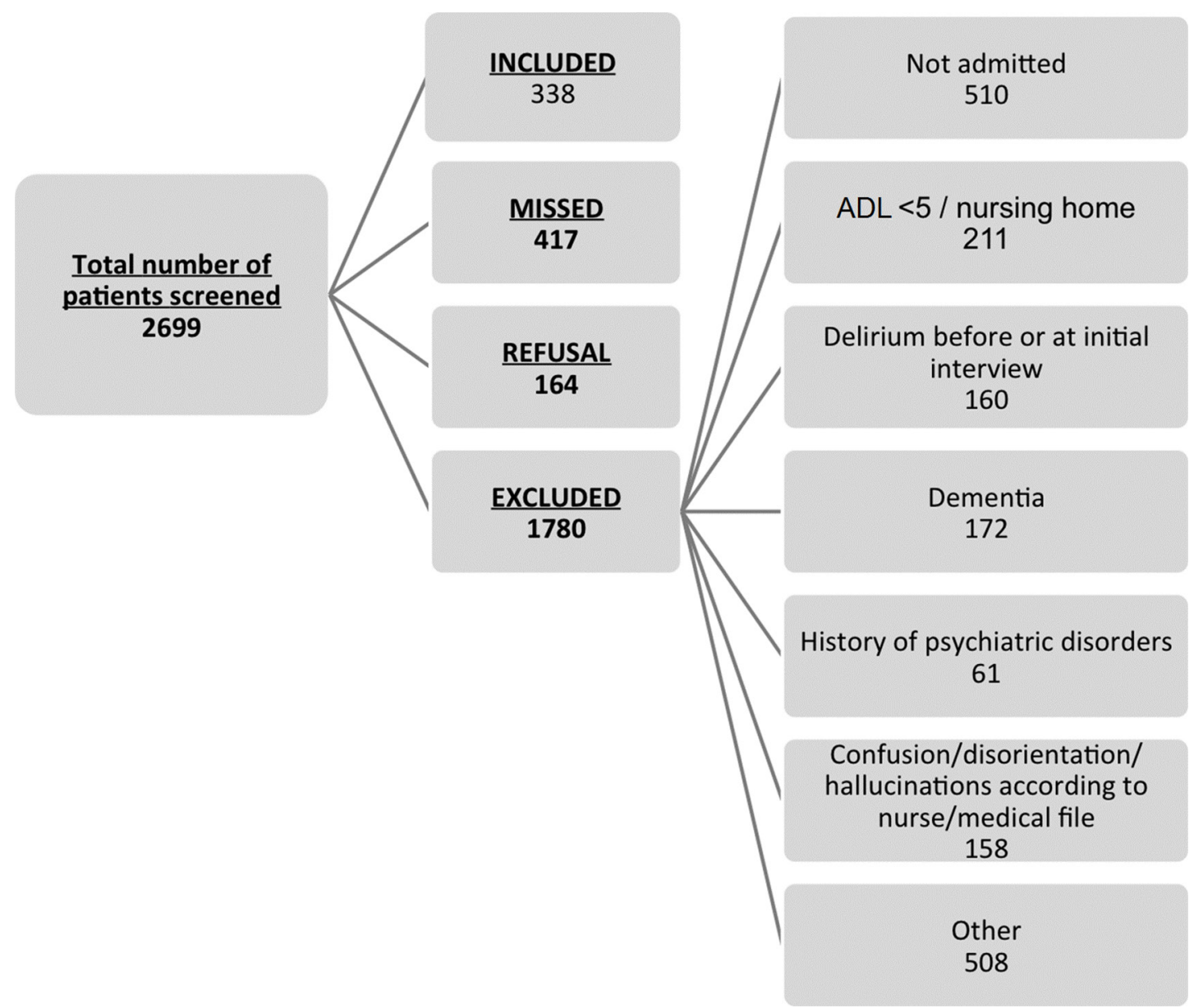

Figure 1 Study flow chart. ADL, activity of daily living.

the healthcare of seniors and on our healthcare system in general.

Caring for older patients in the ED is particularly challenging. ${ }^{10}$ Indeed, the time-pressure environment and high level of background noise may impede efficient communications with older patients. ${ }^{11} 12$ Moreover, specialised geriatric training for ED health professionals remains in its infancy ${ }^{13}$ and they may not be as equipped as they should be to face the specific issues of older patients. All of this may contribute to the fact that older adults have higher rates of unplanned returns to the $\mathrm{ED},{ }^{1415}$ of hospitalisation, ${ }^{16}$ falls, ${ }^{17}$ loss of independence ${ }^{18}$ and unrecognised delirium ${ }^{19-21}$ following an emergency visit. Delirium is an acute brain dysfunction defined as a mental disorder of acute onset with a fluctuating course, characterised by a disturbance in consciousness, attention, orientation, memory, thought, perception and behaviour. ${ }^{22}{ }^{23}$ It is a common problem in the ED and its prevalence in older patients admitted to acute and longterm care facilities ranges between $9.6 \%$ and $89 \%{ }^{21}{ }^{24-26}$

In August of 2013, Inouye et al published a systematic review $^{27}$ in which they found no study reporting the incidence of delirium in the ED. The same author also demonstrated that an ED stay of 12 hours or more was one of the strongest independent predictors of the onset of subsequent delirium in older patients. ${ }^{28-30}$ This is of increasing concern, as recent ED wait times have become quite significant. Since then, a few prospective studies were conducted in order to explore the problem of ED stay-associated delirium. ${ }^{30-32}$ To our knowledge, there are few multicentre studies aimed at describing the incidence of delirium in ED of developed countries, such as Canada. Because the literature regarding the incidence of delirium in the ED and its potential impacts on hospital length of stay (LOS), functional status and unplanned ED readmissions is scant, its consequences have yet to be clearly identified in order to orient modern acute medical care. A study by McCusker et al even found that hospital stay was increased by 7.78 days for patients who developed a delirium (incident delirium) during the first 7 days of their stay. ${ }^{33}$ The onset of such complication in the ED could influence hospital LOS and reflect back on ED crowding and older adults' use of emergency health services. The present study focused on the incidence of delirium induced by ED stay. Although ED-induced delirium could be affected by acute illness, comorbidities, ED crowding metrics and healthcare providers' ability to provide basic care known to prevent delirium, we hypothesised that the incidence of new cases of delirium among older ED patients who are admitted to hospital affects a significant proportion of community older adults, and ED-induced delirium leads to longer hospital LOS 
creating a deleterious feedback loop on ED care and operations. ${ }^{34}$ The study focused on the incident delirium because, as opposed to prevalent delirium, ED services can act in a way to prevent it.

The objective of this study was to fill a basic knowledge gap regarding the incidence of delirium and its impacts on hospital LOS for older, community independent/ semi-independent, non-delirious ED patients with an 8-hour ED stay who are admitted to a hospital ward.

\section{METHODS}

\section{Study setting and population}

This prospective multicentre study included patients who presented to one of the four participating Quebec EDs (two university-affiliated level 1 trauma centres and two regional hospitals) between March and July 2015. Inclusion criteria were: (1) patients aged 65 and over; (2) patients with an ED stay of $\geq 8$ hours; (3) patients needing and/or waiting for admission to any hospital ward and (4) independent or semi-independent patients (able to perform five of seven activities of daily living according to the Older Americans Resources and Services (OARS) scale). Exclusion criteria were: (1) patient with unstable medical condition requiring admission to the psychiatric ward, intensive or palliative care units; (2) patients who are unable to consent; (3) patients who live (or are in transition) in a long-term care facility; (4) patients unable to speak French or English; (5) patients presenting a delirium before coming to the ED, on arrival or by the end of the first 8 hours in the ED and (6) patients with a history of psychiatric disorders (such as schizophrenia, psychotic symptoms and bipolar disorder).

Based on soon to be published new recommendations from the Direction Nationale des Urgences regarding older patients' lengths of ED stay, which should be kept under 8 hours, we choose an 8-hour exposure for our patients, as opposed to the 12-hour exposure previously determined to be a predictor of subsequent delirium. ${ }^{28-30}$ Our pragmatic approach led us to include patients who need or are awaiting admission to a hospital ward; since, Caplan et al showed that patients admitted to hospital have a significantly at higher proportion of delirium than their equivalent counterparts discharged and treated with home resources. ${ }^{35}$ Also, even if we know that delirium is more prevalent in this population, we chose to exclude patients who are not independent or semi-independent, because we were mainly interested to investigate the impact of delirium on the most robust older patients. In addition, we chose to exclude patients who were unable to consent, because assessing initial interview and follow-up with those patients would have been difficult.

Potential participants were identified using the ED information system. Research assistants (RAs) obtained consent and screened the participants for eligibility after their 8-hour exposure to the ED. Sociodemographic, medical and comorbidity data were collected on initial interview. RAs also assessed patients' baseline physical, frailty and cognitive status. Patients were screened for delirium during initial interview, and two times per day (with at least 6 hours between each evaluation) during their entire ED stay and up to 24 hours after being admitted to a hospital ward. We assessed the patient up to 24 hours on the basis that a patient who develops a delirium let say an hour after arrival on the ward is most likely due to the 48 hours in the ED than the first hour on the ward. We kept this evaluation for possible causality purposes. Potential participants were considered as 'missed' when they was no RA on-site for the recruitment. RAs were on site for the screening of patients about 12 hours a day, 7 days a week.

\section{Measures}

Patients' frailty and physical status were assessed using respectively the Clinical Frailty Scale ${ }^{36}$ and the OARS scale,${ }^{37}$ while the modified Telephone Interview for Cognitive Status (TICS-m), ${ }^{38}$ the Confusion Assessment Method $(\mathrm{CAM})^{39}$ and the Delirium Index ${ }^{40}$ were used to assess cognitive status. Other information on medications, comorbidities (Charlson Comorbidity Risk Index), ${ }^{41}$ severity of illness (Acute Physiological and Chronic Health Evaluation II (APACHE II) ${ }^{42}$ and ED environment evaluation were collected in addition to sociodemographic data.

The CAM is the most commonly used tool for the detection of delirium with its sensitivity ranging between $34 \%$ and $58 \%$ and its specificity between $89 \%$ and $94 \%$ when performed by a RA. However, even if this sensitivity seems low, it has been shown that when the CAM is administered several times during a shift, it is more sensitive than a diagnosis made by a psychiatrist. ${ }^{43}$ There are two existing interpretation methods to the CAM scores: the sensitive (SENS) and the specific methods. ${ }^{44}$ A patient has delirium according to the SENS method if they had either an acute onset or a fluctuation in any of the items evaluated in the CAM, inattention and either disorganised thinking or altered state of consciousness. ${ }^{25}$ The SENS method was used to ascertain delirium in this study. Because of the fluctuating nature of delirium, patients were systematically assessed with the CAM and the Delirium Index (a validated tool used to measure the severity of delirium) $)^{40}$ two times per day during their entire ED stay. Furthermore, the CAM was used over a 24-hour period following transfer to the hospital ward. ED and ward nurses and doctors were blinded to the study's objectives in order to avoid them changing their practice. The TICS-m was used to assess baseline cognitive status of our study participants. ${ }^{45}$ ED environmental information, such as presence of proper lighting (according to the RAs), patient's hydration, presence of physical restraints or medical interventions limiting movement at initial interview and presence of a family member or a friend at initial interview was also recorded by RAs. ED LOS was measured from the date and time of triage up to the date and time when the patients were physically transferred to the hospital ward. 
Each site's team of RAs received standardised training by an experienced member of the mentoring team of the Centre d'Excellence sur le Vieillissement de Québec ${ }^{46}$, who also specialises in the administration of the CAM. They also attended a group training session conducted by the study coordinator and an experienced research nurse and underwent a 5-hour personalised field training. They were also provided with a detailed training manual. Interrater reliability was assessed during patient follow-ups at the coordinating site to ensure that the test was administered in a standardised manner.

In order to be sure that the missed patients were similar to our participants, basic clinical and demographic data were collected on those missed patients. The incidence of delirium was also collected for those patients in their medical file, as reported by the ED medical staff.

\section{Outcomes}

Incident delirium was the main outcome of this study, hospital LOS was our secondary outcome. Incident delirium was defined by a delirium who occurred either in the ED or in the first 24 hours of the hospital stay. The CAM was administrated during the initial interview ensuring that the patient was not already delirious after the first 8 hours of their ED stay.

Hospital LOS was also measured from ED triage up to the date and time of hospital discharge. Hospital LOS was compared between patients with a positive CAM and those with a negative CAM for each site.

\section{Statistical analyses}

Descriptive statistics were computed on patient characteristics and measured outcomes. Cumulative incidence rates for delirium were estimated using Kaplan-Meier curves. Hospital LOS is compared in patients with and without incident delirium in the various sites using multiple linear regression, adjusting for ED LOS, APACHE, Charlson, OARS, age and TICS-m. Site and its interaction with incident delirium is treated as a fixed factor. TICS-m scores were adjusted for patients' level of education. Kappa statistics were computed to measure inter-rater reliability of the CAM. Based on an alpha of $5 \%, 138$ patients would allow $80 \%$ power for an estimated overall incidence proportion of $15 \%$ with $5 \%$ precision. Analyses were performed using SAS, V.9.4 (SAS Institute).

Written consent was obtained for each study participant. Patient records/information were anonymised prior to analysis.

\section{RESULTS}

\section{Population}

A total of 2699 patients were screened by RAs across our four sites (figure 1). Of those, 1780 did not meet our inclusion criteria or had one of our exclusion criteria, 417 were missed and 164 refused to participate to the study. This leaves us with a sample of 338 patients (12.5\%).
Females represented $51.2 \%$ of our population and mean age was $76.8( \pm 8.09)$ (table 1$)$.

A sample analysis of patients who were missed revealed that they had a similar profile to that of those who were included in our study. $54.9 \%$ were female, with a mean age of $77.4( \pm 9.4)$ years old. The mean Charlson Comorbidity score was $1.7( \pm 1.7), 36.7 \%$ were considered level 1 or 2 on the Canadian Triage Assessment Scale and 38\% were level 3. The medical notes revealed only one case of incident delirium within 24 hours of triage for this group of patients. Table 1 provides details on sociodemographic and environmental variables.

\section{Incidence of delirium}

In our cohort, we found that the overall incidence of delirium was $12.1 \% \quad(n=41)$ using the SENS method, overall incidence and its distribution across sites are provided in figure 2. Fourteen cases occurred in the ED, while 27 cases occurred on the ward. Our results indicate that the delirium incidence rate was 2.9 cases per 1000 patient-hours. Figure 3 shows a cumulative incidence of delirium curve. Median ED LOS before developing a delirium was 45.2 hours (38.0-52.5). Inter-rater agreements were performed at the coordinating site on $12 \%$ of the site's participants. A perfect agreement was obtained regarding the incidence of delirium, and agreement for each of the CAM items had Kappa ranging between 0.63 and 1.0.

\section{Hospital LOS}

Median (IQR) hospital LOS was 146.6 (75.2-267.8) hours. On average, adjusted hospital LOS was 209 hours (8.7 days) for non-delirious participants while patients who were found to have incident delirium had a 314.4-hour (13.1 days) hospital stay. The hospital LOS for each site is shown in figure 4. Mean hospital-adjusted LOS was significantly increased by 105.4 hours (4.4 days) in the delirious patients compared with non-delirious patient $(\mathrm{P}=0.003)$.

\section{DISCUSSION}

Our study is, to our knowledge, the first large Canadian prospective study aiming to determine the incidence of delirium induced by ED stay in older patients and then to analyse its impacts on the length of in-hospital stay. We found a $12.1 \%$ incidence for delirium in our cohort of 338 older patients. Our study determined that there was a statistically significant association between incident delirium and hospital LOS, which was increased by 4.4 days in patients with incident delirium.

Our results confirm the clinical importance of incident delirium in acute medicine care. A previous Canadian retrospective study was conducted by our team ${ }^{47}$ using a chart-based $\mathrm{CAM},{ }^{48}$ in which an $18 \%$ incidence of delirium was found in 200 patients medical charts. Half of those patients developed a delirium within 36 hours of arrival to the ED. It was shown previously that in prevalent delirious older ED patients that delirium is a predictor of 
Table 1 Description of the study population

\section{Site 1, n (\%) Site 2, n (\%) Site 3, n (\%) Site 4, n (\%) $\quad$ P value $\quad$ Total}

\begin{tabular}{|c|c|c|c|c|c|c|}
\hline \multicolumn{7}{|l|}{ Age } \\
\hline 65-74 years old & $61(57)$ & $21(32)$ & $38(45)$ & $35(42)$ & \multirow[t]{3}{*}{0.001} & $155(46)$ \\
\hline $75-84$ years old & $36(34)$ & $23(35)$ & $35(42)$ & $29(35)$ & & $123(36)$ \\
\hline$\geq 85$ years old & $9(9)$ & $21(32)$ & $11(13)$ & $19(23)$ & & $60(18)$ \\
\hline \multicolumn{7}{|l|}{ Sex } \\
\hline Female & $53(50)$ & $37(57)$ & $39(46)$ & $44(53)$ & 0.618 & $173(51)$ \\
\hline \multicolumn{7}{|l|}{ CTAS } \\
\hline 1 and 2 & $39(37)$ & $25(38)$ & $25(30)$ & $18(22)$ & \multirow[t]{3}{*}{0.076} & $107(31.7)$ \\
\hline 3 & $47(44)$ & $28(43)$ & $43(51)$ & $37(45)$ & & 155 (45.9) \\
\hline 4 and 5 & $20(19)$ & $12(18)$ & $16(19)$ & $28(34)$ & & $76(22.5)$ \\
\hline
\end{tabular}

Admission diagnostic

Medical

\begin{tabular}{|c|c|c|c|c|c|c|}
\hline Cardiology & $15(14.0)$ & $16(21.9)$ & $23(25.2)$ & $16(18.0)$ & & $70(19.4)$ \\
\hline Pneumonology & 22 (20.6) & $15(20.5)$ & $26(28.6)$ & $12(13.5)$ & & $75(20.8)$ \\
\hline Gastroenterology & $13(12.1)$ & $7(9.6)$ & $8(8.8)$ & $17(19.1)$ & & $45(12.5)$ \\
\hline Internal medicine & $6(5.6)$ & $8(11.0)$ & $7(7.7)$ & $8(9.0)$ & & $29(8.1)$ \\
\hline Neurology & $13(12.1)$ & $7(9.6)$ & $9(9.9)$ & $10(11.2)$ & & $39(10.8)$ \\
\hline Other & $28(26.2)$ & $14(19.2)$ & $14(15.4)$ & $21(23.6)$ & & 77 (21.4) \\
\hline \multicolumn{7}{|l|}{ Surgical } \\
\hline Orthopaedics & $2(1.9)$ & $6(8.2)$ & $4(4.4)$ & $5(5.6)$ & & $17(4.7)$ \\
\hline General surgery & $5(4.7)$ & $0(0)$ & $0(0)$ & $0(0)$ & & $5(1.4)$ \\
\hline Other & $3(2.8)$ & $0(0)$ & $0(0)$ & $0(0)$ & & $3(0.8)$ \\
\hline \multicolumn{7}{|l|}{ Time of day of presentation } \\
\hline 0:00-08:00 & $18(16.5)$ & $12(16.2)$ & $21(22.1)$ & $5(5.6)$ & & $56(15.3)$ \\
\hline 08:00-16:00 & $66(60.6)$ & $34(46.0)$ & $43(45.3)$ & $54(60.7)$ & & $197(53.7)$ \\
\hline 16:00-0:00 & $25(22.9)$ & $28(37.8)$ & $31(32.6)$ & $30(33.7)$ & & $114(31.0)$ \\
\hline OARS at baseline $($ mean $\pm S D)$ & $26.33 \pm 1.98$ & $26.41 \pm 2.20$ & $25.95 \pm 2.60$ & $24.92 \pm 2.41$ & $<0.001$ & $25.91 \pm 2.36$ \\
\hline $\begin{array}{l}\text { TICS-m at baseline } \\
(\text { mean } \pm S D)^{*}\end{array}$ & $30.36 \pm 5.68$ & $31.88 \pm 4.69$ & $29.37 \pm 5.92$ & $26.81 \pm 6.70$ & $<0.001$ & $29.53 \pm 6.08$ \\
\hline Charlson $($ mean $\pm S D)$ & $1.93 \pm 1.78$ & $1.65 \pm 1.69$ & $3.13 \pm 2.48$ & $1.81 \pm 1.55$ & $<0.001$ & $2.14 \pm 1.99$ \\
\hline APACHE II (mean \pm SD) & $10.99 \pm 3.43$ & $10.77 \pm 3.37$ & $9.48 \pm 3.43$ & $8.70 \pm 3.17$ & $<0.001$ & $10.01 \pm 3.48$ \\
\hline \multicolumn{7}{|l|}{ Environmental factors } \\
\hline Proper lighting $†$ & $65(63)$ & $49(75)$ & $71(85)$ & $18(22)$ & $<0.001$ & $203(61)$ \\
\hline \multicolumn{7}{|l|}{ Patient hydration } \\
\hline Fasting & $10(10)$ & $8(12)$ & $11(13)$ & $16(19)$ & 0.369 & $45(14)$ \\
\hline Glass of water within reach & $70(72)$ & $55(85)$ & $52(65)$ & $71(86)$ & 0.005 & $248(76)$ \\
\hline Presence of saliva & $74(76)$ & $52(80)$ & $49(60)$ & $9(11)$ & $<0.001$ & $184(56)$ \\
\hline Any intravenous fluids & $75(77)$ & $58(89)$ & 78 (95) & $65(78)$ & 0.003 & $276(84)$ \\
\hline Physical restraints (any)§ & $78(77)$ & $30(46)$ & $1(1)$ & $65(79)$ & $<0.001$ & $174(53)$ \\
\hline \multicolumn{7}{|l|}{$\begin{array}{l}\text { Medical interventions limiting } \\
\text { movement }\end{array}$} \\
\hline Bed rest & $1(1)$ & $1(2)$ & $5(6)$ & $0(0,0)$ & 0.071 & $7(2)$ \\
\hline Urinary catheter & $7(8)$ & $5(9)$ & $2(2)$ & $2(3)$ & 0.217 & $16(6)$ \\
\hline $\mathrm{O}_{2}$ & $15(17)$ & $15(26)$ & $22(27)$ & $4(6)$ & 0.007 & $56(19)$ \\
\hline
\end{tabular}

Continued 


\begin{tabular}{|c|c|c|c|c|c|c|}
\hline & Site 1, n (\%) & Site 2, n (\%) & Site 3, n (\%) & Site 4, n (\%) & $\begin{array}{l}\text { Site } \\
\text { comparison, } \\
\text { P value }\end{array}$ & Total \\
\hline $\begin{array}{l}\text { Saline lock catheter or } \\
\text { intravenous drip }\end{array}$ & $72(84)$ & $53(91)$ & 75 (92) & $57(88)$ & 0.377 & $257(88)$ \\
\hline Other & $10(12)$ & $8(14)$ & $18(22)$ & $6(9)$ & 0.125 & $42(14)$ \\
\hline Temporal orientation aid & $67(63)$ & 45 (69) & $53(63)$ & $37(45)$ & 0.010 & $202(60)$ \\
\hline
\end{tabular}

*Adjusted for level of education.

†According to the RA.

$\ddagger R A$ verified if the patients had saliva under their tongue.

$\S$ Tablet, bed rails or other.

१Clock, watch, cell phone, calendar.

APACHE II, Acute Physiological and Chronic Health Evaluation II; CTAS, Canadian Triage Assessment Scale; OARS, Older Americans

Resources and Services; RA, research assistant; TICS-m, modified Telephone Interview for Cognitive Status.

prolonged hospital LOS. ${ }^{31}$ With our results, we confirm that incident delirium also has such result. However, contrary to prevalent delirium, it is possible to change the interventions in hospital to prevent this episode that has been shown to influence hospital LOS and long-term function and cognition. ${ }^{49}$

In 2011, the Ministère de la Santé et des Services Sociaux has published its provincial guide 'Approche adaptée à la personne âgée en milieu hospitalier, ${ }^{50} \mathrm{a}$ senior-friendly initiative which aimed to better address the in-hospital care of elders. This initiative stresses the importance of keeping lengths of stay as short as possible for older adults and presents various methods to prevent delirium. Every hospital in the province has implemented these guidelines at different levels. However, our results show that over 4 years postimplementation, ED lengths of stay for older patients are still quite significant in Quebec, increasing their risk of developing delirium according to previous studies. Our results also clearly confirm the fact that patients with incident delirium have longer hospital LOS, making them more at risk for further complications. We also recorded an important difference in incident delirium across the four study sites, varying from $8.3 \%$ to

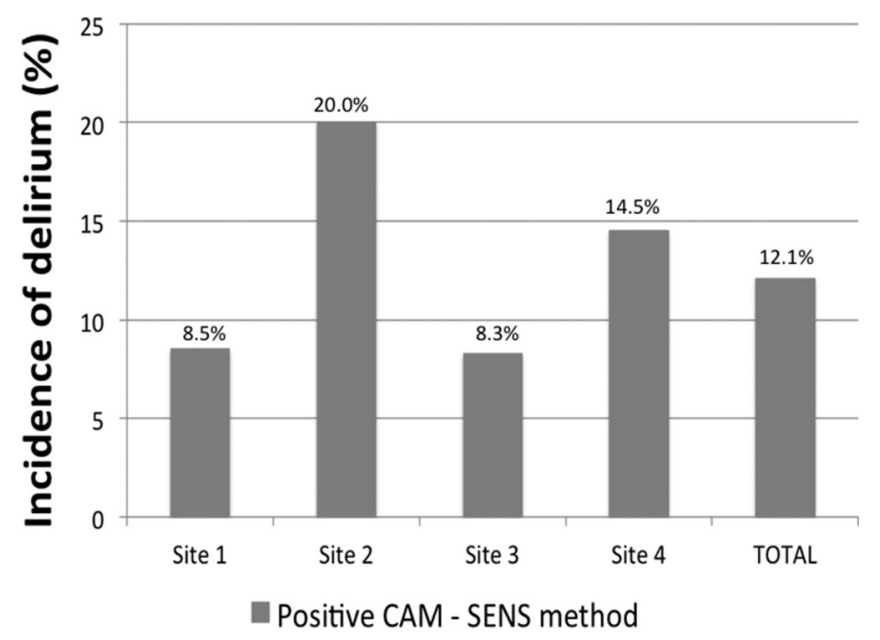

Figure 2 Distribution of delirium across participating sites. CAM, Confusion Assessment Method; SENS, sensitive.
$20 \%$. Although intersite comparisons were not powered by our sample size, many factors could have explained this difference. The different level of implementation of the provincial senior-friendly guidelines at each site could be a possible cause.

This study aimed at assessing the present situation in our Canadian EDs regarding the incidence of delirium induced by a prolonged ED stay in independent and semi-independent older patients. The high incidence rate and increased hospital LOS are alarming and could have substantial consequences for the patient and for our healthcare system in general. Delirium itself is an economic burden in the SA as it is estimated to US\$152 billion per year. ${ }^{31}$

An interesting solution to this issue might be the use of a short triage tool aiming to identify patients more at risk of developing a delirium during their ED stay. Delaney et al found that implementing an alert into the EMR system for triage nurses to screen every patient over 65 years

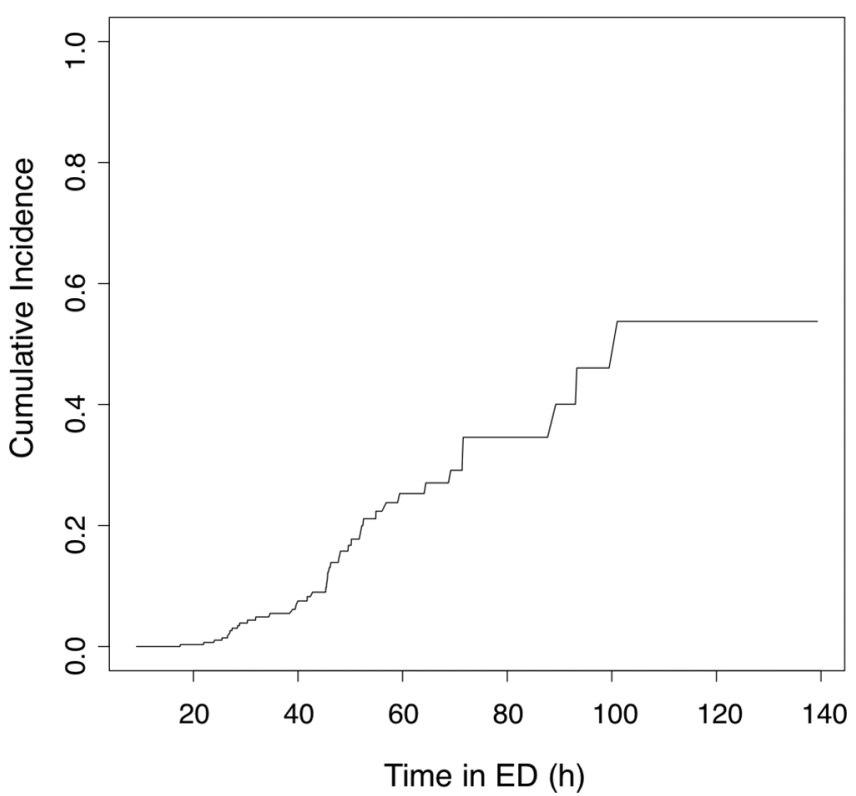

Figure 3 Cumulative incidence of delirium curve. ED, emergency department. 


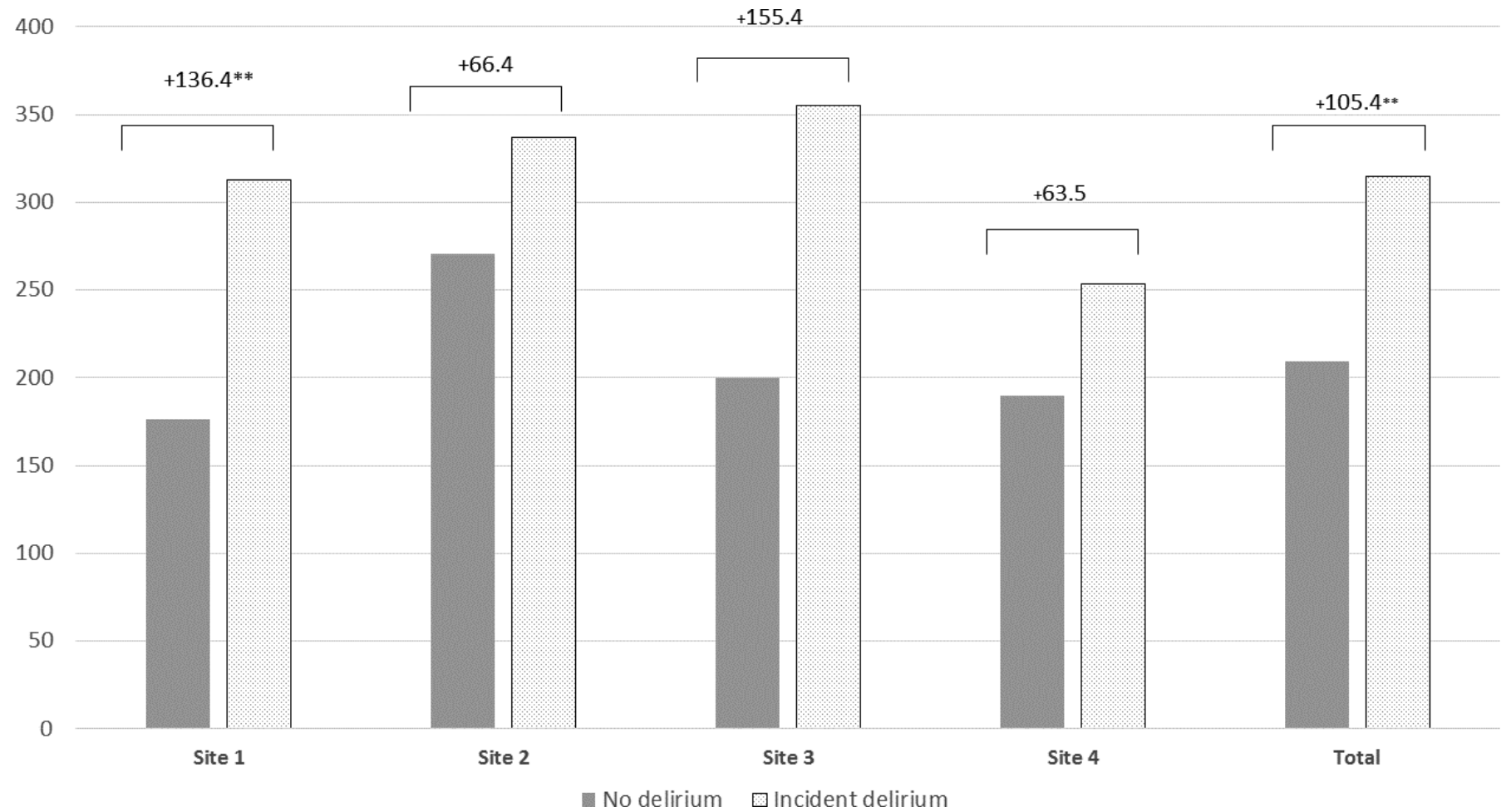

Figure 4 Adjusted length of hospital stay (hours)* . $L e n g t h$ of stay (LOS) was adjusted for ED LOS, site, age, Charlson, APACHE, OARS and TICS-m scores. * Difference between no delirium and incident delirium in terms of length of ED stay $<0.05$. APACHE, Acute Physiological and Chronic Health Evaluation; ED, emergency department; OARS, Older Americans Resources and Services; TICS-m, modified Telephone Interview for Cognitive Status.

old for delirium helped ED nurses better identify $23 \%$ of patients as potentially positive for delirium..$^{32}$ However, more research is needed in order to identify an appropriate tool to be used by triage nurses. A better identification of patients at high risk for delirium could permit to apply some prevention protocols previously proposed. ${ }^{51}$

Our study has some limitations. Our high rate of missed patients is mainly due to logistic constraints. However, after comparing the sociodemographic characteristics and comorbidities, we have found no significant difference between patients who were included and those who were missed. Furthermore, including those missed patients would likely have reinforced our results, resulting in higher delirium rates and longer ED and hospital LOS. Therefore, we believe the likelihood of selection bias is low. Because we have chosen to exclude patients with moderate to severe dementia, those who lived in longterm nursing homes, those with pre-existing psychological conditions and patients who had a lesser functional level, our cohort represents only a portion of the older adult population usually seen in the ED and may not be generalisable to all elders. We have made this decision because we were mainly interested to investigate the impact of delirium on the most robust older patients. The CAM was administered by different RAs, and therefore this might have underestimated or overestimated the frequency of an acute onset of a new symptom. Misclassification of delirium may have occurred as we excluded patient with delirium using a single first initial assessment with CAM, this pragmatic approach was used to ensure feasibility of the study. This may have introduced an interviewer bias; however, this situation is not any different from real-life clinical practice. We tried to decrease this potential bias by providing RAs with standardised training, which was proven effective given our good interobserver agreement. The study coordinator also reviewed every single research file to ensure completeness.

In conclusion, the incidence of delirium was $12.1 \%$ in community-dwelling older adults enrolled from four Canadian EDs. Incident delirium significantly increased hospital LOS by 4 days and could possibly negatively affect the patient and healthcare system.

\section{Author affiliations}

${ }^{1}$ Axe Santé des populations et pratiques optimales en santé, Centre de recherche du CHU de Québec-Université Laval, Québec, Canada

Département de médecine d'urgence, CHU de Québec-Université Laval, Québec, Canada

${ }^{3}$ Medicine, Université Laval, Québec, Canada

${ }^{4}$ Centre d'excellence sur le vieillissement de Québec, Québec, Canada

${ }^{5}$ Centre de recherche sur les soins et les services de première ligne de l'Université Laval, Québec, Canada

${ }^{6}$ Centre interdisciplinaire de recherche en réadaptation et intégration sociale, Québec, Canada

${ }^{7}$ Nursing, Université Laval, Québec, Canada

${ }^{8}$ Centre Intégré de Santé et de Services Sociaux de Lanaudière, Joliette, Canada

${ }^{9}$ Centre Hospitalier Régional de Trois-Rivières, Trois-Rivières, Canada

${ }^{10} \mathrm{Centre}$ de recherche de l'Hôpital du Sacré-Cœur de Montréal, Montréal, Canada

${ }^{11}$ Medicine, Université de Montréal, Montréal, Canada

${ }^{12}$ Centre de recherche du Centre hospitalier de l'Université de Montréal, Montréal, Canada 
${ }^{13}$ Centre hospitalier de l'Université de Montréal, Montréal, Canada

${ }^{14}$ Institut de gériatrie de l'Université de Montréal, Montréal, Canada

${ }^{15}$ CSSS de Trois-Rivières, Trois-Rivières, Canada

${ }^{16}$ Centre Intégré Universitaire de Services Sociaux et de Santé de la CapitaleNationale, Québec, Canada

${ }^{17}$ Department of Family and Community Medicine, University of Toronto, Toronto, Canada

${ }^{18}$ Sunnybrook Health Sciences Center, Toronto, Canada

Acknowledgements We would like to thank all the research assistants who participated in the recruitment of patients.

Contributors MÉ had full access to all of the data in the study and takes responsibility for the integrity of the data and the accuracy of the data analysis. He was responsible for design, funding, conduct of the study and writing of the manuscript. VB managed the study, led the analyses and wrote the manuscript. MÉ, VB and P-HC were involved in the statistical analysis and data interpretation. MP, RD, ÉG and M-EL were responsible for recruitment at all four sites. PV, SB, MM, TTMV, JL, MR, SL, NLS and LJ are all collaborators of INDEED project. P-HC, MP, RD, ÉG, M-EL, PV, SB, MM, TTMV, AN, JL, MR, SL, NLS and LJ reviewed and approved the manuscript.

Funding This study was funded by the Fond Québécois de Recherche en Santé (FQRS 29307).

Competing interests None declared.

Patient consent Obtained.

Ethics approval The Comité d'éthique du CHU de Québec acted as the centralised research ethics board and approved this study (project number MP-20-2015-2130).

Provenance and peer review Not commissioned; externally peer reviewed.

Data sharing statement Being a prospective observational multicentre study, this project includes other data results to be solely used by our research team. The data use follows the framework governed by a public funding agency (FQRS).

Open Access This is an Open Access article distributed in accordance with the Creative Commons Attribution Non Commercial (CC BY-NC 4.0) license, which permits others to distribute, remix, adapt, build upon this work non-commercially, and license their derivative works on different terms, provided the original work is properly cited and the use is non-commercial. See: http://creativecommons.org/ licenses/by-nc/4.0/

(c) Article author(s) (or their employer(s) unless otherwise stated in the text of the article) 2018. All rights reserved. No commercial use is permitted unless otherwise expressly granted.

\section{REFERENCES}

1. Gouvernement du Québec - Institut de la statistique du Québec. Le bilan démographique du. Québec, 2016.

2. Heffler S, Levit K, Smith S, et al. Health Spending Growth Up In 1999; Faster Growth Expected In The Future. Health Aff 2001;20:193-203.

3. Data warehouse on trends in health and aging. 2002 www.cdc.gov/ nchs/about/otheract/aging/trenddata.htm

4. Mathews M, Barnsley J. Patients seeking care during acute illness. Why do they not see their regular physicians? Can Fam Physician 2003:49:1498-503.

5. Hahn B, Lefkowittz D. Annual expenses and sources of payment for health care services. Agency For Health Care Policy and Research, Public Health Service: Rockville, MD, 1992. 14 DHHS Pub. No AHCPR 93-0007.

6. Le Commissaire à la santé et au bien-être (CSBE). Les Urgences au Québec: Évolution de 2003-2004 à 2012-2013, 2014.

7. Burt CW, McCaig LF. Trends in hospital emergency department utilization: United States, 1992-99. Vital Health Stat 13 2001;13150:1-34.

8. McCaig LF, Burt CW. National Hospital Ambulatory Medical Care Survey: 2002 emergency department summary. Adv Data 2004;340:1-34

9. Delafuente JC. The silver tsunami is coming: will pharmacy be swept away with the tide? American journal of pharmaceutical education. 2009;73:1.

10. Hwang $U$, Morrison RS. The geriatric emergency department. J Am Geriatr Soc 2007;55:1873-6.
11. Baraff LJ, Bernstein E, Bradley K, et al. Perceptions of emergency care by the elderly: results of multicenter focus group interviews. Ann Emerg Med 1992;21:814-8.

12. Moons $\mathrm{P}$, Arnauts $\mathrm{H}$, Delooz $\mathrm{HH}$. Nursing issues in care for the elderly in the emergency department: an overview of the literature. Accid Emerg Nurs 2003;11:112-20.

13. Hedges JR, Singal BM, Rousseau EW, et al. Geriatric patient emergency visits. Part II: Perceptions of visits by geriatric and younger patients. Ann Emerg Med 1992;21-808-13.

14. Boult C, Dowd B, McCaffrey D, et al. Screening elders for risk of hospital admission. J Am Geriatr Soc 1993;41:811-7.

15. Friedmann PD, Jin L, Karrison TG, et al. Early revisit, hospitalization, or death among older persons discharged from the ED. Am J Emerg Med 2001;19:125-9.

16. Marcantonio ER, McKean S, Goldfinger M, et al. Factors associated with unplanned hospital readmission among patients 65 years of age and older in a Medicare managed care plan. Am J Med 1999;107:13-17.

17. Speechley $M$, Tinetti $M$. Falls and injuries in frail and vigorous community elderly persons. J Am Geriatr Soc 1991;39:46-52.

18. Aminzadeh F, Dalziel WB. Older adults in the emergency department: a systematic review of patterns of use, adverse outcomes, and effectiveness of interventions. Ann Emerg Med 2002;39:238-47.

19. Hustey FM, Meldon SW. The prevalence and documentation of impaired mental status in elderly emergency department patients. Ann Emerg Med 2002;39:248-53.

20. Han JH, Zimmerman EE, Cutler N, et al. Delirium in older emergency department patients: recognition, risk factors, and psychomotor subtypes. Acad Emerg Med 2009;16-193-200.

21. Elie M, Rousseau F, Cole M, et al. Prevalence and detection of delirium in elderly emergency department patients. CMAJ 2000;163:977-81.

22. Cole MG. Delirium in elderly patients. Am J Geriatr Psychiatry 2004;12:7-21.

23. Han JH, Wilber ST. Altered mental status in older patients in the emergency department. Clin Geriatr Med 2013;29:101-36.

24. Fick DM, Agostini JV, Inouye SK. Delirium superimposed on dementia: a systematic review. J Am Geriatr Soc 2002;50:1723-32.

25. Lemiengre J, Nelis T, Joosten E, et al. Detection of delirium by bedside nurses using the confusion assessment method. J Am Geriatr Soc 2006;54:685-9.

26. Voyer P, Richard S, Doucet L, et al. Detecting delirium and subsyndromal delirium using different diagnostic criteria among demented long-term care residents. J Am Med Dir Assoc 2009;10:181-8.

27. Inouye SK, Westendorp RG, Saczynski JS. Delirium in elderly people. Lancet 2014:383:911-22.

28. Inouye SK, Viscoli CM, Horwitz RI, et al. A predictive model for delirium in hospitalized elderly medical patients based on admission characteristics. Ann Intern Med 1993;119:474-81.

29. Inouye SK, Charpentier PA. Precipitating factors for delirium in hospitalized elderly persons. Predictive model and interrelationship with baseline vulnerability. JAMA 1996;275:852-7.

30. Bo $\mathrm{M}$, Bonetto $\mathrm{M}$, Bottignole $\mathrm{G}$, et al. Length of stay in the emergency department and occurrence of delirium in older medical patients. J Am Geriatr Soc 2016;64:1114-9.

31. Han JH, Eden S, Shintani A, et al. Delirium in older emergency department patients is an independent predictor of hospital length of stay. Acad Emerg Med 2011;18-451-7.

32. Delaney M, Pepin J, Somes J. Emergency department delirium screening improves care and reduces revisits for the older adult patient. J Emerg Nurs 2015;41:521-4.

33. McCusker J, Cole MG, Dendukuri N, et al. Does delirium increase hospital stay? J Am Geriatr Soc 2003;51:1539-46.

34. Forster AJ, Stiell I, Wells G, et al. The effect of hospital occupancy on emergency department length of stay and patient disposition. Acad Emerg Med 2003;10:127-33.

35. Caplan GA, Coconis J, Woods J. Effect of hospital in the home treatment on physical and cognitive function: a randomized controlled trial. J Gerontol A Biol Sci Med Sci 2005;60-1035-8.

36. Rockwood K, Song X, MacKnight C, et al. A global clinical measure of fitness and frailty in elderly people. CMAJ 2005;173-489-95.

37. Fillenbaum GG, Duke U. Multidimensional functional assessment of older adults: the Duke Older Americans Resources and Services procedures. Hillsdale, NJ: L. Erlbaum Associates, 1988:179.

38. de Jager CA, Budge MM, Clarke R. Utility of TICS-M for the assessment of cognitive function in older adults. Int $J$ Geriatr Psychiatry 2003;18:318-24.

39. Inouye SK, van Dyck CH, Alessi CA, et al. Clarifying confusion: the confusion assessment method. A new method for detection of delirium. Ann Intern Med 1990;113:941-8. 
40. McCusker J, Cole MG, Dendukuri N, et al. The delirium index, a measure of the severity of delirium: new findings on reliability, validity, and responsiveness. J Am Geriatr Soc 2004;52:1744-9.

41. Frenkel WJ, Jongerius EJ, Mandjes-van Uitert MJ, et al. Validation of the Charlson Comorbidity Index in acutely hospitalized elderly adults: a prospective cohort study. J Am Geriatr Soc 2014;62:342-6.

42. Knaus WA, Draper EA, Wagner DP, et al. APACHE II: a severity of disease classification system. Crit Care Med 1985;13:818-29.

43. Zou Y, Cole MG, Primeau FJ, et al. Detection and diagnosis of delirium in the elderly: psychiatrist diagnosis, confusion assessment method, or consensus diagnosis? Int Psychogeriatr 1999;10:303-8.

44. Inouye S. CAM Training Manual. New Haven: CT: Yale University School of Medicine, 1991.

45. Herr M, Ankri J. A critical review of the use of telephone tests to identify cognitive impairment in epidemiology and clinical research. $J$ Telemed Telecare 2013;19:45-54.

46. Centre intégré universitaire de santé et de services sociaux de la Capitale-Nationale. Centre d'excellence sur le vieillissement de Québec, 2017. https://www.ciusss-capitalenationale.gouv.qc.ca/ expertise-et-partenariat/le-centre-dexcellence-sur-le-vieillissementde-quebec

47. Émond M, Grenier D, Morin J, et al. Emergency department stay associated delirium in older patients. Can Geriatr J 2017;20:10-14.

48. Inouye SK, Leo-Summers L, Zhang Y, et al. A chart-based method for identification of delirium: validation compared with interviewer ratings using the confusion assessment method. J Am Geriatr Soc 2005;53:312-8

49. Han $\mathrm{JH}$, Vasilevskis EE, Chandrasekhar R, et al. Delirium in the Emergency Department and Its Extension into Hospitalization (DELINEATE) Study: Effect on 6-month Function and Cognition. J Am Geriatr Soc 2017;65:1333-8.

50. Ministère de la Santé et des Services Sociaux. Approche adaptée à la personne âgée en milieu hospitalier - Cadre de référence, 2011.

51. Abraha I, Trotta F, Rimland JM, et al. Efficacy of NonPharmacological Interventions to Prevent and Treat Delirium in Older Patients: A Systematic Overview. The SENATOR project ONTOP Series. PLoS One 2015;10:e0123090-31. 